\title{
Anaesthesia for Caesarean section in a patient with Jervell, Lange-Nielsen syndrome
}

The anaesthetic management of a patient with Jervell, LangeNielsen syndrome (a form of congenitally protonged $Q T$ interval) requiring emergency Caesarean section is presented. An epidural anaesthetic using 3-chloroprocaine produced a safe and satisfactory anaesthetic for the procedure in a patient prone to ventricular arrhythmias and cardiac arrest. High levels of circulating catecholamines have been pastulated as one of the causes of the arrhythmias in these patients, making it advisable to select drugs and sechniques known to minimize catecholamine levels. Although communication can be difficult in these profoundly deaf patients, it is important in order to reduce the emotional stress. Elective Caesarean sections under general anaesthesia have been reported; it appears that a well planned regional anaesthetic is equally safe.

There are several varieties of the prolonged QT syndrome (long QT syndrome, LQTS) which might either present as a congenital form of the disease, or be acquired in later life. ${ }^{-5}$ A case of Jervell, Lange-Nielsen (JLNS, cardioauditory or surdocardiac) syndrome is presented. This autosomal recessively inherited syndrome consists of a prolonged QT interval, neural deafness and syncopal attacks secondary to ventricular tachycardia, ventricular fibrillation or asystole, or sudden death.

The patient whose case is reported was known to have JLNS and required an anaesthetic to facilitate an emergency Caesarean section.

\section{Key words}

ANAESTHESIA: epidural, Caesarean section; sYNDROME: Jervell, Lange-Nielsen syndrome, prolonged QT syndrome.

From the Department of Anesthesia, University Hospital and University of Saskatchewan, College of Medicine, Saskatoon, Saskatchewan S7N OX0.

\section{Case report}

A 19-year-old deaf Caucasian female presented at 38 weeks' gestalion in early labour. She had a history of multiple syncopal attacks in childhood, which were fairly well controlled from age seven onwards by beta adrenergic blockers (initially propranolol, then atenolol, when depression and lethargy developed while the patient was receiving propranolol). At age 12 ventricular fibrillation and cardiac arrest occurted while she was en route to the dentist; after resuscitation she remained in the Intensive Care Unit for one week with aspiration pneumonia, mild hypoxic encephalopathy (from which she made a gradual recovery) and recurrent ventricular tachycardia that was controlled by lidocaine. During childhood the QT interval ranged from 0.66 to 0.49 seconds.

Family history revealed a cousin with syncopal attacks who died suddenly at age 22 and another cousin with prolonged QT syndrome, deafness and a seizure disorder.

On admission to hospital the patient's heart rate was 73 heats per minute; the electrocardiogram (ECG) revealed a QTc of 0.54 second. After initiation of ECG monitoring of the patient, syntocinon augmentation was begun. An initial fetal tracing showed poor variability and late decelerations that improved slightly after syntocinon was discontinued and oxygen was administered. As maternal beta-blockade can cause fetal hypoxia, and might attenuate the usual signs of fetal distress, ${ }^{7}$ the obstetrician planned a Caesarean section as scon as possible.

Epidural anaesthesia was selected because it was thought that a rapid-sequence induction and intubation might produce sufficient stress to induce dysrhythmias. Great care was taken to explain the procedure fully to the patient in order to reduce anxiety; since she was profoundly deaf and could not lip-read, this was accomplished with the assistance of a hospital social worker fluent in sign language. The epidural catheter was easily inserted in the $\mathrm{L}_{3-4}$ interspace and a test dose of $3 \mathrm{ml}$ of two per cent lidocaine without epinephrine was injected. In some patients with LQTS, lidocaine has caused further prolongation of the QTc. ${ }^{2}$ This, coupled with the difficulty in 
communication of symptoms, should an inadvertent intravascular injection occur, lead us to chose an ester, 3-chloroprocaine, over lidocaine or bupivacaine. Incremental $(3-5 \mathrm{ml})$ boluses were given until analgesia was obtained to the level of $\mathrm{T}_{4}$, a total of $30 \mathrm{ml}$ being given for the entire procedurc. In the cvent that volume expansion and uterine displacement did not maintain the blood pressure, small $(2.5 \mathrm{mg}$ ) doses of ephedrine would be given; however, both blood pressure and heart rate remained stable. Intravenous diazepam $2.5 \mathrm{mg}$ was given after the delivery of a healthy boy (Apgar scores of eight at one minute and nine at five minutes), and epidural morphine 4 mg was given at the end of the case for postoperative pain relief. ECG monitoring was continued for three hours postoperatively; her condition remained stable, the QTC was 0.51 second $(0.54$ second preoperatively) and she was discharged to the wars. She and the baby did well, and were both discharged five days postoperatively. Five months later she had another cardiac arrest, from which she was resuscitated. She was unconscious and required mechanical ventilation for two days and had another arrest during that time. She was discharged in ten cays with only a memory loss and unsteady gait as sequelae. A few wecks later after an argument with her husband she became pale and shaky. This had resolved and her ECG was as usual by the time she arrived in the Emergency Department.

\section{Discussion}

The Jervell-Lange Neilsen syndrome is rare; while the incidence is estimated to be 1 in 300,000 in the gencral population, the syndrome occurs in one per cent of patients with congenital deafness. ${ }^{8}$ The true incidence is difficult to determine as many with the condition die in infancy or childhood if not treated.

The abnormal tepolarization of the cardiac muscle in these patients results from an inbalance in the cardiac sympathetic innervation. The imbalance is likely due to either decreased activity in the right cardiac sympathetic nerves (chronotropic activity) or perhaps to an increased activity of the left (inotropic activity). The altered sympathetic tone results in delayed ventricular repolarization, increasing the susceptibility to dysrhythmias. Adrenergic stimulation from physical or emotional stress or from exogenous adrenergic drugs might precipitate dysrhythmias. ${ }^{2}$ Other proposed locations for the autonomic imbalance are the brain-stcm, sympathetic chain or adrenergic nerve terminals. ${ }^{2}$ Another possible machanism is a deficient blood supply to the sinus node resulting in ischaemia or infarction causing sinus pacemaker failure which allows escape beats to develop. There may also be an enzymatic deficiency or metabolic abnormality causing the LQTS. ${ }^{2}$ In 1975, Schwartz et al. reported that of
68 patients receiving no treatment 74 per cent died in infancy or childhood; of 79 patients receiving beta blockers six per cent died in infancy, childhood or early adulthood. Other medications that have been successfully used are phenytoin, phenobarbitone, primidone, calcium entry blockers, bretylium and lidocaine in acute attacks. Left stellate ganglion block or ganglionectomy has also been successful in blocking the sympathetic imbalance. ${ }^{9}$

In the anaesthetic management of these patients, reduction of both emotional and physical stress is of paramount importance. This is achieved by establishing good communication and rapport between the patient and medical staff, and by selecting anaesthetic agents and techniques that minimize either catecholamine release or cardiac sensitivity to catecholamines. Communication through an interpreter is time-consuming, but necessary to reduce anxiety. Emotional stress may have serious or even potentially fatal consequences, as is illustrated by the accurrence of a cardiac arrest in this patient seven years previously. This patient presented a challenge in that she was first made known to the anaesthesia department when she arrived in labour with signs of fetal distress.

There are few reports of anaesthesia for pregnant patients with LQTS. One report of labour in a patient with idiopathic LQTS mentions epidural anaesthesia being used for forceps extraction, but does not describe the anaesthetic management. ${ }^{10}$ Another report details two elective Caesarean sections in a patient with JLNS done utilizing general anaesthesia (diazepam was given as pre-medication, a rapid-sequence induction with thiopentone and succinylcholine was followed by maintenance with nitrous oxide, oxygen and halothane). ${ }^{8}$ In the present case a general anacsthetic was considered undesirable as the fetal distress would necessitate a light anaesthetic which, because of the maternal catecholamine release and subsequent risk of arthythmias was to be avoided.

Regional (epidural) anaesthesia can be safely used for Caesarean section in patients with LQTS, with certain caveats acknowledged. The usual dose of beta-blockers should be continued, supplemented with intravenous propranolol as necessary. Stress, drugs, and techniques releasing adrenalin should be avoided, although pure alpha agonists or low doses of mixed vasoconstrictors are theoretically safe. Adequate hydration and proper positioning are the desirable methods of prevention of hypotension. With respect to drug selection, operations such as Caesarean section might require doses of local anaesthetics sufficient to cause systcmic toxicity in the absence of epinephrine, yet the latter is to be avoided. ${ }^{2}$ Alternative drugs (as chosen for this patient), or careful titration with avoidance of intravascular injection is required to prevent disaster. As in every case provision must be made for emergency defibrillation and resuscita- 
tion should it be needed, and neonatal management including prevention of bradycardia and hypogylcaemia secondary to beta-blockade must be available.

\section{Acknowledgements}

The author wishes to thank Flo Welch in assisting in the preparation of this case report and Dr. D. Burris for his assistance in the case.

\section{References}

1 Jervell A, Lange-Nielson F. Congenital deaf mutism, functional heart disease with prolongation of the $Q T$ interyal and sudden dzath. Am Heart J 1957; 54: 59-68.

2 Galloway PA, Glass PSA. Anacsthetic implications of prolonged QT syndrome. Anesth Analg 1985; 64: 612 20.

3 Wilton NCT, Hantler $C P$. Congenital long QT syndrome: changes in QT interval during anesthesia with thiopental, vecuronium, fentanyl, and isoflurane. Anesth Analg 1987; 66: 357-60.

4 Kenny RA, Sutton $R$. The prolonged QT interval - a fre quently unrecognized abnomality. Postgrad Med J 1985; 61: 379-86.

5 Baze $H C$. An analysis of the time-relations of electrucardiograms. Heart 1920; 7: 353-70.

6 Moss AJ, Schwariz PJ. Sudden death and idiopathic long QT syndrome. Am J Med 1979; 66: 6-7.

7 Cosmi EV. Obstetric Anesthesia and Perinatology, Chapter 15: Drugs and anesthetics in the management of preterm labor and delivery. 1981 p. 560 . AppletonCentury-Crofts/New York.

8 Freshwater $J V$. Anaesthesia for Caesarean section and the Jervell, Lange-Nielson syndrome (prolonged QT inteIval syndrome). Br J Anaesth 1984; 56: 655-7.

9 Schwartz PJ, Periti M, Malliani A. The long QTsyndrome. Am Heart I 1975; 89: 398-90.

10 Bruner JP, Barry MJ. Elliott J8. Pregnancy in a patient with idiopathic long QT syndrome. Am I Obstet Gynecol 1984; 144: 690-1.

\section{Resumê}

La conduite anesthesique d'une patiente atteint du svidrome de Jervell, Lange-Nielsen (une forme congénitale d'un intervalle Qr prolongé) requérant une césarienne d'urgence est présen. tée. Une anesthésie épidurale utilisant le 3-chloroprocaïne était sécuritaire et satisfaisante paur la procédure chez une paiente susceptible de développer des arythmies ventriculaires et un arrêt cardiaque. Des taux élevés de catécholantines circulantes ont été suggérés comme étant l'une des causes lie ces aryrhmies chez ces patientes rendant plus sécuritaire le choix de dragues et de techniques connues comme pouvant diminuer le taux de ces catécholamines. Même si la communication est difficile avec ces patients atteints de surdité elle est importante afin de diminuer le stress émotionnel. L'anesthésie générale pour une césarienne élective a été rapportée chez ces patientes et il apparaît qu'une anesthésie régionale bien planifiée est aussi sécuritaire. 